\title{
Effect of Calotropis procera (madar) and amprolium supplementation on parasitological parameters of broilers during mixed Eimeria species infection
}

\author{
Sakshi Chauhan ${ }^{1}$, V. S. Singh ${ }^{1}$ and Vipul Thakur ${ }^{2}$
}

1. Department of Veterinary Parasitology, College of Veterinary and Animal Sciences, G.B. Pant University of Agriculture and Technology, Pantnagar - 263 145, Uttarakhand, India;

2. Department of Veterinary Public Health and Epidemiology, Lala Lajpat Rai University of Veterinary and Animal Sciences, Hisar, Haryana, India.

Corresponding author: Sakshi Chauhan, e-mail: sakshichauhan35840@gmail.com

Co-authors: VSS: singhvs65@gmail.com, VT: vipulthakur29153@gmail.com

Received: 31-12-2016, Accepted: 23-06-2017, Published online: 05-08-2017

doi: 10.14202/vetworld.2017.864-868 How to cite this article: Chauhan S, Singh VS, Thakur V (2017) Effect of Calotropis procera (madar) and amprolium supplementation on parasitological parameters of broilers during mixed Eimeria species infection, Veterinary World, 10(8): 864-868.

\begin{abstract}
Aim: An experiment was conducted on day old 168 broiler chicks to study the effect of $0.4 \%$ as well as $0.2 \%$ Calotropis procera (madar) leaf powder and $0.0125 \%$ amprolium supplementation on parasitological parameters of broilers during mixed Eimeria species infection.

Materials and Methods: Chicks were randomly divided into seven groups (I-VII) each with two replicates of 12 chicks. On $15^{\text {th }}$ day of experiment, broilers of Group II, IV, VI, and VII were infected with 50,000 sporulated oocysts of mixed Eimeria species. To evaluate the anticoccidial effect of different feed supplements percent fecal score, percent survival, percent weight gain, performance index (PI), average oocyst production, and percent reduction in oocyst production were calculated.
\end{abstract}

Results: It was observed that amprolium supplementation had maximum anticoccidial effect as it gave the best efficacy in terms of all parameters, whereas supplementation of $0.4 \%$ madar leaf powder showed nonsignificant difference with amprolium for some parameters such as percent survival, percent weight gain, and PI.

Conclusion: It can be concluded that madar (C. procera) leaf powder and amprolium had comparable activity against coccidiosis. Hence, madar leaf powder may be used for the prevention and control of mixed Eimeria spp. infection prevalent in field conditions.

Keywords: amprolium, Calotropis procera, coccidiosis, parasitological parameters.

\section{Introduction}

Coccidiosis is one of the most dangerous diseases of poultry [1]. Coccidiosis is commonly called as red dysentery. It is caused by the intracellular protozoan parasite Eimeria, which undergoes its life cycle in the intestinal mucosa of the infected bird. Parasites present a monoxenous life cycle and are transmitted by the oral-fecal route. Eimeria may lead to a massive epithelial destruction. Consequently, the host may suffer with diarrhea, malabsorption, and poor weight gain [2].

Control of coccidiosis in modern intensive poultry production is based on the use of chemical coccidiostats in feed of poultry [1], but along with the problem of drug resistance, there are also food safety and public health concerns about drug residues in poultry products [3] which limit their use. Difficulties in tackling avian coccidiosis stimulated the scientists

\footnotetext{
Copyright: Chauhan, et al. Open Access. This article is distributed under the terms of the Creative Commons Attribution 4.0 International License (http://creativecommons.org/licenses/ by/4.0/), which permits unrestricted use, distribution, and reproduction in any medium, provided you give appropriate credit to the original author(s) and the source, provide a link to the Creative Commons license, and indicate if changes were made. The Creative Commons Public Domain Dedication waiver (http:// creativecommons.org/publicdomain/zero/1.0/) applies to the data made available in this article, unless otherwise stated.
}

to explore further newer methods of control, and the natural products are being investigated to this effect [4]. Plant products (phytobiotics or phytogenics) could provide an alternative means of coccidia control to which resistance has not yet developed [5]. An important medicinal plant, Calotropis procera, has many pharmacological properties as antioxidant, antidiarrhea, anti-inflammatory, analgesic, antiulcer, antimicrobial, hepatoprotective, antipyretic, and antiparasitic activity [6]. Looking to the medicinal properties of madar present experiment was conducted to evaluate the anticoccidial effect of madar (C. procera) leaf powder in comparison with the standard anticoccidial Amprolium.

\section{Materials and Methods \\ Ethical approval}

This study was conducted after necessary approval from advisory and Institutional Animal Ethics Committee of College of Veterinary and Animal Sciences, G.B. Pant University of Agriculture and Technology, Pantnagar.

\section{Study area}

Experiment was conducted in the College of Veterinary and Animal Sciences, G.B. Pant University 
of Agriculture and Technology, Pantnagar. For the experiment, 168, one-day-old commercial broiler chicks were randomly allocated to seven groups. The groups were designated as Groups I, II, III, IV, V, VI, and VII. Each group had two replicates having 12 chicks. The broilers were reared in electrically heated battery cages located in shed with $24 \mathrm{~h}$ light and ventilation. The cages were cleaned, washed and disinfected before each experiment and were fitted with separate feeders and waterers for different treatments. At the age of 5 days, vaccination against Ranikhet disease and at 12 days, vaccination against Gumboro disease was done using $\mathrm{F}_{1}$ strain and Georgia strain vaccine, respectively. Experiment was conducted for 30 days. Coccidiostat free feed for the broilers was brought from local poultry feed supplier. Feed given to all groups of broilers was isonitrogenic and isocaloric. Feed and drinking water were provided ad-libitum to the broilers during the entire experimental period. Broilers of Groups I and II were provided standard control diet without any supplement. In broilers of Groups III and IV, standard feed was supplemented with $0.0125 \%$ amprolium and broilers of Groups V and VI were provided with basal diet supplemented with $0.2 \%$ madar leaf powder. Broilers of Group VII were provided standard control diet supplemented with $0.4 \%$ madar leaf powder.

\section{Oocysts isolation}

To isolate the oocysts of Eimeria sp., method described by Holdswort et al. [7] was used with few modifications. Oocysts were washed with water before use, and then the number of oocysts was counted in McMaster chamber [8]. Eimeria spp. mixed culture contained Eimeria tenella (80\%), Eimeria necatrix $(10 \%)$, Eimeria acervulina (6\%), E. maxima $(2 \%)$, and Eimeria mitis (2\%), which were identified on the basis of guidelines of Levine [9]. At the age of 15 days, broilers of Groups II, IV, VI, and VII were infected by inoculating $1 \mathrm{ml}$ suspension containing 50,000 sporulated oocysts of mixed Eimeria species directly in the pharynx, using a long nozzled $2 \mathrm{ml}$ plastic pipette. Broilers of various groups, viz., I, III, and $\mathrm{V}$ were inoculated with $1 \mathrm{ml}$ plain water.

\section{Evaluation of anticoccidial effect of different supplementations}

To evaluate the anticoccidial effect of different feed supplements percent fecal score, percent survival, percent weight gain, performance index (PI), average oocyst production, and percent reduction in oocyst production were calculated in different groups.

Percent fecal score was calculated from $4^{\text {th }}$ to $10^{\text {th }}$ day postinfection as per the method described by Morehouse and Baron [10]. For this fecal collection trays of control as well as supplemented groups were divided into four parts and fecal score of each division was scored every day as 0 to +4 . Percent fecal score for each supplemented infected group was determined as under:
Percent fecal score $=$

Total of highest fecal score for each division in control infected group - Total of highest faecal score for each division in supplemented infected group $\times 100$

Total of highest fecal score for each division in control infected group

Percent fecal score thus obtained was rounded to nearest $5 \%$.

To determine percent survival chicks were observed daily for the clinical manifestation and mortality after introduction of infection. Percent weight gain was calculated for each group from the formula given below:

Percent weight gain $=$

Mean weight gain of supplemented

infected group $\times 100$

Mean weight gain of control

uninfected group

PI was calculated by adding percent survival, percent weight gain, and percent fecal score [10].

Fecal oocyst count was carried out from $4^{\text {th }}$ to $14^{\text {th }}$ day postinfection by collecting feces from each infected subgroup [8], and then average oocyst count was calculated. Percent reduction in oocyst production was calculated by the formula given below:

Percent reduction in oocyst production $=$

No. of oocysts produced by control

infected group -

No. of oocysts produced by

supplemented infected

No. of oocysts produced by control $\times 100$

infected group

\section{Statistical analysis}

All the observations recorded were subjected to statistical analysis using one-way ANOVA technique described by Snedecor and Cochran [11].

\section{Results}

Parasitological parameters were absent in uninfected groups, so only infected groups were considered for statistical analysis.

Percent fecal score, percent survival, percent weight gain, and PI in all infected groups are presented in Table-1 and Figure-1.

Broilers of Group IV (78.00) had maximum and significantly higher percent fecal score, whereas Groups VI (59.50) and VII (66.00) had intermediate percent fecal score which differ nonsignificantly with each other. 
Table-1: Effect of different supplementations on percent fecal score, percent survival, percent weight gain and performance index in experimental broiler chicks.

\begin{tabular}{llcccc}
\hline \multicolumn{2}{l}{ Groups } & *Percent fecal score & *Percent survival & *Percent weight gain & *Performance index \\
\hline II & IC & $0.00 \pm 0.00^{\mathrm{c}}$ & $75.00 \pm 00^{\mathrm{b}}$ & $71.35 \pm 0.93^{\mathrm{c}}$ & $146.35 \pm 0.93^{\mathrm{c}}$ \\
IV & IA & $78.00 \pm 4.24^{\mathrm{a}}$ & $100 \pm 0.00^{\mathrm{a}}$ & $93.89 \pm 0.06^{\mathrm{a}}$ & $271.89 \pm 4.18^{\mathrm{a}}$ \\
VI & IM-1 & $59.50 \pm 4.24^{\mathrm{b}}$ & $95.84 \pm 5.89^{\mathrm{a}}$ & $89.20 \pm 0.33^{\mathrm{b}}$ & $244.54 \pm 10.46^{\mathrm{b}}$ \\
VII & IM-2 & $66.00 \pm 4.60^{\mathrm{b}}$ & $95.84 \pm 5.89^{\mathrm{a}}$ & $93.44 \pm 0.16^{\mathrm{a}}$ & $255.03 \pm 10.33^{\mathrm{ab}}$ \\
\hline
\end{tabular}

*Significant; $a, b, c$ Means bearing different superscripts in a column differ significantly $(p \leq 0.05)$. IC $=$ Infected untreated control, IA=Infected supplemented with amprolium, IM-1 =Infected supplemented with $0.2 \%$ madar leaf powder, IM-2=Infected supplemented with $0.4 \%$ madar leaf powder

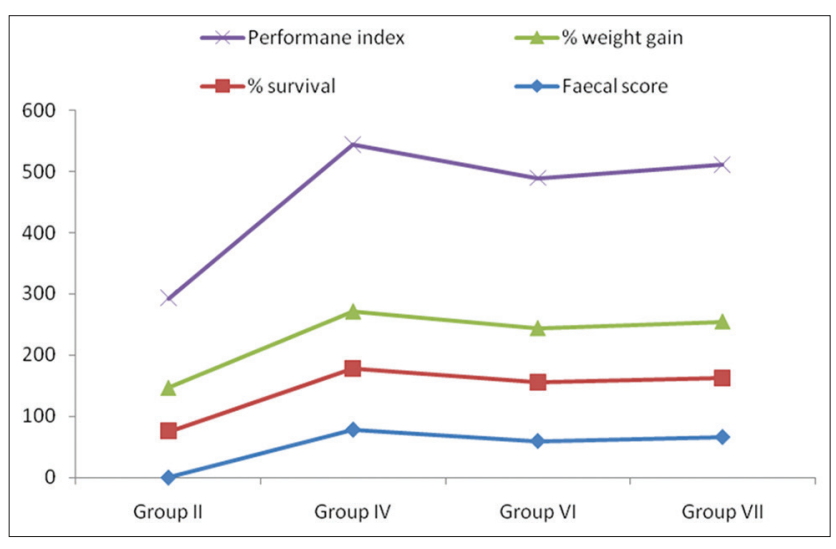

Figure-1: Effect of different supplementations on \% faecal score, \% survival, \% weight gain and performance index in experimental broiler chicks.

Percent survival in broilers of infected untreated group, i.e., Group II (75.00) was lowest, whereas in Groups VI and VII percent survival was 95.84 and it was non-significantly lower than that of Group IV, which had cent percent survival. Similarly, Tipu et al. [12], Biu et al. [13], and Hady and Zaki [14] also observed lowest percent survival in control infected groups and increase in survival percent with the use of herbs. Biu et al. [13] observed that amprolium showed 100 percent survival rates against mixed Eimeria spp. oocysts.

Percent weight gain was highest in broilers of Group IV (93.89\%) which differed nonsignificantly to broilers of Group VII (93.44\%). Significantly lower and minimum percent weight gain was recorded in broilers of Group II (71.35\%). Allen et al. [15] and Wang et al. [16] also reported increased body weight gain by dietary supplementation of herbal formulations in Eimeria spp. infected chickens. Abbas et al. [17] also found significantly higher $(\mathrm{p} \leq 0.05)$ weight gain in the groups infected with $E$. tenella and treated with $3 \%$ turmeric than that of infected control group.

PI of broilers of Group IV (271.89) was maximum, which was nonsignificantly higher than that of Group VII (255.03). PI of Group VII was also nonsignificantly different to Group VI (244.54), while significantly minimum PI was recorded in broilers of Group II (146.35). PI being the sum of percent fecal score, percent survival, and percent weight gain was improved due to the amprolium and herbal supplementation. Singh et al. [18] also recorded higher PI in sprouted mung supplemented group than control infected group.
Average oocyst production and percent reduction in percent oocyst production in all infected groups are presented in Table-2 and Figure-2.

Average oocyst production per gram of feces was 239250 in broilers of Group II, which was lower in all the supplemented groups and minimum for Group IV (25775). Groups VI (52825) and VII (47150) had intermediate average oocyst production, and these values were significant amid all the groups $(\mathrm{p} \leq 0.05)$. Oocyst production was significantly less in all supplemented groups than control infected group. Zaman et al. [19] also found that after Eimeria infection total oocyst production was lower in C. procera containing herbal complex treated and amprolium treated groups than control infected group. Mahmoud et al. [20] also observed the inhibiting effect of $C$. procera on oocyst production against Eimeria ovinoidalis in lambs.

There was no reduction in percent oocyst production in broilers of Group II, but in other groups, significant reduction in oocyst production was noticed. Group IV (89.23) had maximum percent reduction followed by Group VII (80.29) and Group VI (77.92). The present report is also in agreement with Tipu et al. [12] and Singh et al. [21] who used herbal anticoccidials and found similar results. Singh et al. [22] also noticed reduction in oocyst production with herbal vitamin E-selenium supplementation against mixed Eimeria spp. oocysts.

\section{Discussion}

Plants produce a broad-spectrum variety of phytochemicals such as phenolics, polyacetylenes, alkaloids, polysaccharides, terpenoids, and essential oils with a large number of antimicrobial bioactivities [23]. Safe alternative to chemical anticoccidial drug is herbal products because they do not results to tissue residue and drug resistance [24]. The results of this study show the effectiveness of amprolium and madar for control of coccidiosis. Anticoccidial effect of madar leaf powder may be attributed to its anticoccidial property due to its saponin content, which act on the protozoan development by interacting with cholesterol present on the parasitic cell membrane and resulting into parasitic death $[16,19]$ and phenols and flavonoids contents, which contribute to its antioxidant property and limit Eimeria induced damage to the intestinal wall during pro-inflammation reaction and resulting in less damage to the gut [25]. Antidiarrheal 


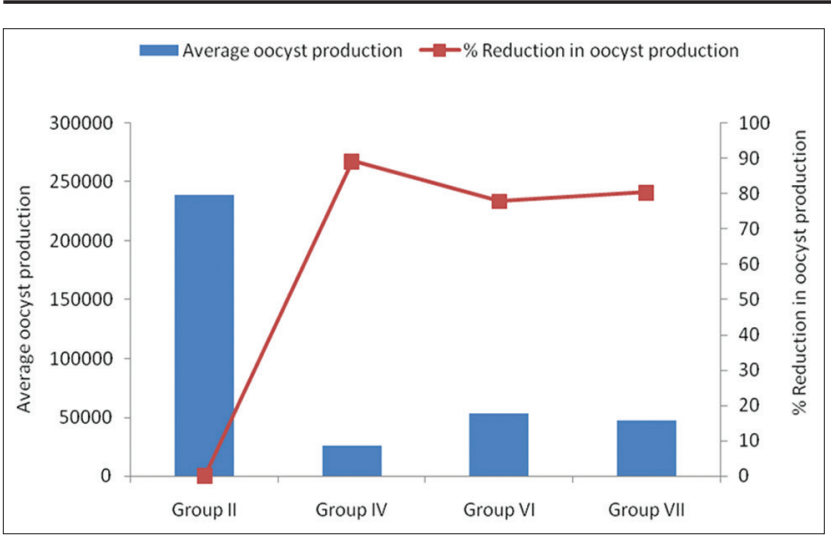

Figure-2 : Effect of different supplementations on average oocyst production and \% reduction in oocyst production in experimental broiler chicks.

Table-2: Effect of different supplementations on average oocyst production and \% reduction in oocyst production in experimental broiler chicks.

\begin{tabular}{llcc}
\hline Groups & $\begin{array}{c}\text { *Average oocyst } \\
\text { production }\end{array}$ & $\begin{array}{c}\text { *Percent reduction in } \\
\text { oocyst production }\end{array}$ \\
\hline II & IC & $239250 \pm 1343.50^{\mathrm{a}}$ & $00 \pm 0.00^{\mathrm{d}}$ \\
IV & IA & $25775 \pm 1025.31^{\mathrm{d}}$ & $89.23 \pm 0.43^{\mathrm{a}}$ \\
VI & IM-1 & $52825 \pm 459.62^{\mathrm{b}}$ & $77.92 \pm 0.19^{\mathrm{c}}$ \\
VII & IM-2 & $47150 \pm 212.13^{\mathrm{c}}$ & $80.29 \pm 0.08^{\mathrm{b}}$ \\
\hline
\end{tabular}

*Significant; $a, b, c, d$ Means bearing different superscripts in a column differ significantly $(p \leq 0.05)$. IC $=$ Infected untreated control, IA=Infected supplemented with amprolium, IM-1=Infected supplemented with $0.2 \%$ madar leaf powder, IM-2=Infected supplemented with $0.4 \%$ madar leaf powder

and antiulcer property of madar leaf powder also contributed to its anticoccidial effect [26,27]. El-Khtam et al. [28] also evaluated anticoccidial efficacy of Allium sativum powder and turmeric powder against coccidiosis in broilers which may be due to their antioxidant properties. Carica papaya suppresses coccidiosis by proteolytic destruction of Eimeria by papain and anti-inflammatory action by vitamin A [29]. Garlic and its sulfur compounds, i.e., allicin, alliin, ajoene, diallyl sulfide, dithiin, and allylcysteine, are reported to have broad antimicrobial activities. An in vitro study has shown that allicin inhibits sporulation of E. tenella effectively [30]. Green tea extracts significantly inhibited the sporulation process of coccidian oocysts. The selenium and polyphenolic compounds in green tea are thought to be active compounds to inactivate the enzymes responsible for coccidian sporulation [31].

\section{Conclusion}

Considering the parasitological parameters, amprolium supplementation had maximum anticoccidial effect in terms of all parameters; however, supplementation of $0.4 \%$ madar leaf powder showed nonsignificant difference with amprolium for some parameters such as PI, percent survival, and percent weight gain. Hence, it can be concluded that anticoccidial effect showed by $0.4 \%$ madar leaf powder was comparable to that of amprolium and anticoccidial effect of $0.4 \%$ madar leaf powder was more than $0.2 \%$ madar leaf powder against mixed Eimeria spp. infection. Hence, madar leaf powder may be used for the prevention of mixed Eimeria spp. infection prevalent in field conditions.

\section{Authors' Contributions}

SC carried out the study. VSS helped in collection of samples, planning and supervision of the study. VT helped in data analysis and designing of the manuscript. All authors read and approved the manuscript.

\section{Acknowledgments}

The authors are thankful to the Dean, College of Veterinary and Animal Sciences, G.B. Pant University of Agriculture and Technology, Pantnagar, Uttarakhand, India, for fund and providing necessary facilities during the course of the study.

\section{Competing Interests}

The authors declare that they have no competing interests.

\section{References}

1. Allen, P.C. and Fetterer, R.H. (2002) Recent advances in biology and immune biology of Eimeria species and in diagnosis and control of infection with these coccidian parasites of poultry. Clin. Microbiol. Rev., 15: 58-65.

2. Novaes, J., Thibirio, L., Rangel, L.D., Ferro, M., Abe, R.Y., Manha, A.P.S., De Mello, J.C.M., Varuzza, L., Durham, A.M., Madeira, A.M.B.N. and Grub, A. (2012) A comparative transcriptome analysis reveals expression profiles conserved across three Eimeria spp. of domestic fowl and associated with multiple developmental stages. Int. J. Parasitol., 42: 39-48.

3. McDougald, L.R. and Seibert, B.P. (1998) Residual activity of anticoccidial drugs in chickens after withdrawal of medicated feeds. Vet. Parasitol., 74: 91-93.

4. Kayser, O., Kiderlen, A.F. and Croft, S.L. (2003) Natural products as antiphrastic drugs. Parasitol. Res., 90: 55-62.

5. Abbas, R.Z., Colwell, D.D. and Gilleard, J. (2012) Botanicals: An alternative approach for the control of avian coccidiosis. World Poult. Sci. J., 68: 203-215.

6. Kumar, P.S., Suresh, E. and Kalavathy, S. (2013) Review on a potential herb Calotropis gigantea (L.) R. Br. Sch. Acad. J. Pharm., 2(2): 135-143.

7. Holdswort, P.A., Conway, D.P., McKenzie, M.E., Dayton, A.D., Chapman, H.D., Mathis, G.F., Skinner, J.T., Mundt, H.C. and Williams, R.B. (2004) World association for the advancement of veterinary parasitology (WAAVP) guidelines for evaluating the efficacy of anticoccidial drugs in chickens and turkeys. Vet. Parasitol., 121: 189-212.

8. Davies, S.F.M., Joyner, L.P. and Kendall, S.B. (1963) Coccidiosis. $1^{\text {st }}$ ed. Oliver and Boyd Ltd., Edinburg. p221.

9. Levine, N.D. (1985) Veterinary Protozoology. Iowa State University Press, Ethopia. p414.

10. Morehouse, N.F. and Baron, R.R. (1970) Coccidiosis: Evaluation of coccidiostats by mortality, weight gains and faecal scores. Exp. Parasitol., 28: 25-29.

11. Snedecor, G.W. and Cochran, W.G. (1994) Statistical Methods. $8^{\text {th }}$ ed. Iowa University Press, Iowa, U.S.A.

12. Tipu, M.A., Pasha, T.N. and Ali, Z. (2002) Comparative efficacy of salinomycin sodium and neem fruit (Azadirachta Indica) as feed additive anticoccidials in broilers. Int. J. Poult. Sci., 1(4): 91-93.

13. Biu, A.A., Yusuff, S.D. and Rabo, J.S. (2006) Use of neem 
(Azadrichata indica) aqueous extract as a treatment for poultry coccidiosis in Borno State, Nigeria. Afr. Sci., 7(3): 147-151.

14. Hady, M.M. and Zaki, M.M. (2012) Efficacy of some herbal feed additives on performance and control of cecal coccidiosis in broilers. APCBEE Procedia, 4: 163-168.

15. Allen, P.C., Danforth, H.D. and Augustine, P.C. (1998) Dietary modulation of avian coccidiosis. Int. J. Parasitol., 28: 1121-1140.

16. Wang, Y., Mcallister, T.A., Newbold, C.J., Rode, L.M., Cheeke, P.R. and Cheng, K.J. (1998) Effects of Yucca schidigera extract on fermentation and degradation of steroidal saponins in the rumen simulation technique (RUSITEC). Anim. Feed Sci Technol., 74: 143-153.

17. Abbas, R.Z., Iqbal, Z., Khan, M.N., Zafar, M.A. and Zia, M.A. (2010) Anticoccidial activity of Curcuma longa L. In broiler chickens. Braz. Arch. Biol. Technol., 53: 63-67.

18. Singh, V.S., Palod, J., Vatsya, S., Kumar, R.R. and Shukla, S.K. (2013a) Effect of sprouted mung (Vigna radiata) supplementation on performance of broilers during mixed Eimeria species infection. Vet. Res. Int., 1(2): 41-45.

19. Zaman, M.A., Iqbal, Z., Abbas, R.Z. and Khan, M.N. (2011) Anti-coccidial activity of herbal complex in broiler chickens challenged with Eimeria tenella. Parasitology, 139(2): 237-243.

20. Mahmoud, O.M., Haroun, E.M., Sobaih, M.A., Omer, O.H. and Adam, S.E.I. (2001) Comparative efficacy of Calotropis procera latex and sulfadimidine against experimentally-induced Eimeria ovinoidalis infection in Najdi lambs. Small Rum. Res., 42(2): 135-140.

21. Singh, V.S., Palod, J., Shukla, S.K. and Shukla, P.K. (2008) Influence of a herbal anticoccidial on growth, parasitological, haematological parameters and carcass traits of the broilers experimentally infected with mixed field isolates of Eimeria species. Indian J. Anim. Sci., 78(10): 1057-1062.

22. Singh, V.S., Palod, J., Vatsya, S. and Shukla, S.K. (2013b)
Effect of herbal vitamin E-selenium with organic chromium on growth, hematological and parasitological parameters of broilers chicken during mixed Eimeria infection. Vet. Res. Int. , 1(1): 25-30.

23. Muthamilselvan, T., Kuo, T., Wu, Y. and Yang, W. (2016) Herbal remedies for coccidiosis control: A review of plants, compounds, and anticoccidial actions. Evid Based Complement Altern. Med., 2016: 1-19.

24. Habibi, H., Firouzi, S., Nili, H., Razavi, M., Asadi, S.L. and Daneshi, S. (2016) Anticoccidial effects of herbal extracts on Eimeria tenella infection in broiler chickens: In vitro and in vivo study. J. Parasit. Dis., 40(2): 401-407.

25. Bozkurt, M., Giannenas, I., Kucukyilmaz, K., Christaki, E. and Florou-Paneri, P. (2013) An update on approaches to controlling coccidia in poultry using botanical extracts. Br. Poult. Sci., 54(6): 713-727.

26. Chitme, H.R., Chandra, R. and Kaushik, S. (2004) Studies on anti-diarrhoeal activity of Calotropis gigantea R.Br. In experimental animals. J. Pharm. Pharm. Sci., 7: 70-75.

27. Kshirsagar, A., Patil, P.A., Ashok, P. and Hulkoti, B. (2008) Anti-inflammatory and anti-ulcer effects of Calotropis gigantean R.Br flowers in rhodents. J. Nat. Rem., 8(2): 183-190.

28. El-Khtam, A.O., Latif, A.A.E. and El-Hewaity, M.H. (2014) Efficacy of turmeric (Curcuma longa) and garlic (Allium sativum) on Eimeria species in broilers. Int. J. Basic Appl. Sci., 3(3): 349-356.

29. Nghonjuyi, N.W. (2015) Efficacy of ethanolic extract of Carica papaya leaves as a substitute of sulphanomide for the control of coccidiosis in KABIR chickens in Cameroon. J. Anim. Health. Prod., 3(1): 21-27.

30. Alnassan, A.A., Thabet, A., Daugschies, A. and Bangoura, B. (2015) In vitro efficacy of allicin on chicken Eimeria tenella sporozoites. Parasitol. Res., 114(10): 3913-3915.

31. Molan, L. and Faraj, A.M. (2015) Effect of selenium-rich green tea extract on the course of sporulation of Eimeria oocysts. J. Dent. Med. Sci., 14(4): 68-74.

\section{$* * * * * * * *$}

